Research Paper

\title{
Elevated Plasma Matrix Metalloproteinase-9 and Its Correlations with Severity of Disease in Patients with Ventilator-Associated Pneumonia
}

\author{
Yia-Ting Li $1^{1,2^{*}}$, Yao-Chen Wang $3,4^{*}$, Hsiang-Lin Lee ${ }^{1,5}$, Min-Chi Lu ${ }^{6,7 凶}$, Shun-Fa Yang1,8凶 \\ 1. Institute of Medicine, Chung Shan Medical University, Taichung, Taiwan; \\ 2. Division of Respiratory Therapy, Department of Internal Medicine, Chung Shan Medical University Hospital, Taichung, Taiwan; \\ 3. Division of Pulmonary Medicine, Department of Internal Medicine, Chung Shan Medical University Hospital, Taichung, Taiwan; \\ 4. School of Medicine, Chung Shan Medical University, Taichung, Taiwan; \\ 5. Division of Gastroenterology, Department of Surgery, Chung Shan Medical University Hospital, Taichung, Taiwan; \\ 6. Division of Infectious Diseases, Department of Internal Medicine, China Medical University Hospital, Taichung, Taiwan; \\ 7. Department of Microbiology and Immunology, School of Medicine, China Medical University, Taichung, Taiwan; \\ 8. Department of Medical Research, Chung Shan Medical University Hospital, Taichung, Taiwan. \\ *These authors contributed equally to the work.
}

$\square$ Corresponding authors: Shun-Fa Yang, PhD. Or Min-Chi Lu, MD., PhD. Institute of Medicine, Chung Shan Medical University, 110 Chien-Kuo N. Road, Section 1, Taichung 402, Taiwan; Phone: 886-4-2473959, ext. 34253; Fax: 886-4-24723229; E-mail: ysf@csmu.edu.tw (Shun-Fa Yang); luminchi@gmail.com (Min-Chi Lu).

() Ivyspring International Publisher. Reproduction is permitted for personal, noncommercial use, provided that the article is in whole, unmodified, and properly cited. See http://ivyspring.com/terms for terms and conditions.

Received: 2016.05.16; Accepted: 2016.07.13; Published: 2016.07.26

\begin{abstract}
Ventilator-associated pneumonia (VAP) increases patient mortality and medical expenditure, and a real-time and reliable method for the rapid diagnosis of VAP may help reduce fatal complications. Matrix metalloproteinases-9 (MMP-9) is considered significant in the pathogenesis of lung inflammation and infection. Therefore, we examined its relationship with the clinical course of VAP. This retrospective observational study recruited 30 healthy volunteers, 12 patients who used mechanical ventilation without the development of VAP (hereafter, patients without VAP), and 30 patients with a clinical diagnosis of VAP (hereafter, patients with VAP). The activity and level of plasma MMP-9 were determined through a gelatin zymography assay and ELISA. Our results report that both plasma MMP-9 activity and concentration were significantly elevated in the acute stage of patients with VAP when compared with control group and patients without VAP $(p<$ 0.001 ). Subsequently, the plasma MMP-9 of patients with VAP decreased significantly after antibiotic treatment. Furthermore, plasma MMP-9 concentration was positively correlated with the clinical pulmonary infection score $(r=0.409, p=0.007)$, WBCs $(r=0.620, p<0.001)$, and neutrophils counts $(r=0.335, p=0.035)$. In addition, plasma MMP-9 is an excellent tool for recognizing VAP when the cutoff level is set to $92.62 \mathrm{ng} / \mathrm{mL}$ (AUC $=0.863,95 \% \mathrm{Cl}=0.761$ to 0.932). In conclusions, we concluded that MMP-9 levels play a role in the development of VAP and might have the potential to be applied in the development of VAP therapies.
\end{abstract}

Key words: Ventilator-associated pneumonia, MMP-9, pulmonary infection score.

\section{Introduction}

Ventilator-associated pneumonia (VAP) is one of the most common infectious diseases in the intensive care unit and occurs in patients who receive mechanical ventilator support for more than $48 \mathrm{~h}$ [1]. The incidence varies from $6 \%-52 \%$ and is associated with a high mortality rate ranging from $20 \%-76 \%$ [2].
Therefore, developing an effective measure to decrease the incidence of VAP has always been an imperative challenge. Numerous clinical standards have been developed to diagnose VAP, but none of the evaluation systems have sufficient sensitivity or specificity [3]. Misdiagnosis can lead to treatment 
failure and increase the risk of mortality. In addition, it may increase the incidence of drug resistance and clinical severity, prolonging mechanical ventilation support and the length of hospital stay, all of which result in increased mortality and total medical expenditure. Therefore, developing a reliable and timely detection method for diagnosing VAP is imperative, and specific proteins (biomarkers) whose presence is correlated with the disease have been used to facilitate diagnosis [4].

In the pathogenesis of pneumonia, matrix metalloproteinases-9 (MMP-9) (type IV collagenase 92 $\mathrm{kDa}$, gelatinase B), which belongs to a large family of zinc-dependent endopeptidases [5], is vital in immune response [6, 7]. It is generated by various cells, including keratinocytes, monocytes, tissue macrophages, polymorphonuclear leukocytes, and even malignant cells. During inflammation, MMP-9 activates specific proteins and promotes neutrophil migration into the alveolar compartment to maintain immune response [8]. Moreover, MMP-9 is essential for neutrophils to generate reactive oxygen species and leads to inflammation and tissue damage in the pathogenesis of Mycoplasma pneumoniae pneumonia [9]. Furthermore, MMP-9 has also been proposed to serve as an anti-inflammatory mediator, by degrading ECM proteins and modifying chemokines, to avoid excessive neutrophil recruitment into the lung $[7,10]$.

Because MMP-9 has been significantly associated with the pathogenesis of pneumonia, we hypothesized that MMP-9 may facilitate the early recognition of VAP. To the best of our knowledge, no published study has investigated the diagnostic value of plasma MMP-9 in a cohort of patients with VAP. Herein, we compared plasma MMP-9 protein levels among groups of patients with a clinical diagnosis of VAP (hereafter, patients with VAP), control patients who have used a mechanical ventilator without subsequent VAP development (hereafter, patients without VAP), and healthy control volunteers in order to evaluate whether MMP-9 could be a useful biomarker in helping identify VAP.

\section{Materials and methods}

\section{Study population and blood sample collection}

This retrospective observational study was conducted during June 2012-June 2014 in the intensive care units and respiratory care ward of Chung Shan Medical University Hospital (CSMUH) in Taichung, Taiwan. In total, 72 patients were recruited, including 30 healthy volunteers, 12 patients without VAP who underwent various surgeries $(\mathrm{n}=$ $10)$, had neurological conditions $(\mathrm{n}=1)$, or experienced cardiovascular failure $(\mathrm{n}=1)$, and 30 patients with VAP. All 30 healthy volunteers were recruited at the same hospital and these control groups had no inflammation diseases or cancer of any sites. Patients' baseline characteristics, namely age, gender, reasons for initiating mechanical ventilation support, coexisting illnesses, severity of VAP (which was classified by the clinical pulmonary infection score (CPIS)), and respiratory parameters (including $\mathrm{PF}$ ratio $=\mathrm{PaO}_{2} / \mathrm{FiO}_{2}$ and oxygenation index; $\mathrm{OI}=$ $\mathrm{FiO}_{2} \times$ mean airway pressure $/ \mathrm{PaO}_{2}$ ) were recorded. In patients with VAP, blood samples were obtained both in the acute stage of VAP (within 5 days from the onset of VAP) and in the remission stage (within $10 \pm$ 3 days from the onset of VAP). Blood samples from patients without VAP were collected $48 \mathrm{~h}$ after initiating ventilation support. Blood samples were also collected from the control group. The blood samples were infused into EDTA-coated tubes and were immediately centrifuged and stored at $-80{ }^{\circ} \mathrm{C}$. The study was approved by the Institutional Review Board of CSMUH (IRB No.CS12040), and informed consent was received from each participant.

\section{Diagnostic criteria for VAP}

The diagnosis of VAP was based on the guidelines of the American Thoracic Society [11]. The diagnostic criteria included mechanical ventilation for at least $48 \mathrm{~h}$, a new or progressive radiographic infiltrate, and at least two of the following: fever (body temperature $>38{ }^{\circ} \mathrm{C}$ ), purulent tracheal secretions, or leukocytosis or leukopenia (leukocyte count $>10,000 / \mu \mathrm{L}$ or $<4,000 / \mu \mathrm{L}$, respectively). Only patients with a positive semiquantitative bacterial culture (SQ-EA), which demonstrated moderate growth, from the endotracheal aspirate were included in category of patients with VAP. Patients were excluded if they were $<20 y$ of age, immunosuppressed, or had a coexisting extrapulmonary infection during the study period.

\section{Gelatin Zymography}

The MMP-9 activity in the plasma samples were analysed using gelatin zymography assay as previously described. $20 \mu \mathrm{l}$ of each plasma sample was loaded onto a precast sodium dodecyl sulfate-polyacrylamide (SDS-PAGE) gel containing $0.1 \%$ gelatin for electrophoresis. Gels were then processed as described by Yeh et al. [12], with nonstaining bands representing MMP-9 activities. The MMP-9 activities were assessed after the relative photographic densities of MMP-9 were compared by scanning the photographic negatives on a gel documentation and analysis system (AlphaImager 2000; Alpha Innotech Corporation, San Leandro, CA). 


\section{Measurement of plasma MMP-9 levels}

The MMP-9 levels in the plasma samples were analysed using human MMP-9 enzyme-linked immunosorbent assay (ELISA) kits (R\&D Systems, Abingdon, UK) as previously described [13]. Briefly, $100 \mu \mathrm{L}$ of diluted samples were added to the wells of an ELISA plate and incubated at $37^{\circ} \mathrm{C}$ for $2 \mathrm{hr}$, and then $100 \mu \mathrm{L}$ of anti-human MMP-9 antibody was added into each well. After washing three times with $400 \mu \mathrm{L}$ washing buffer, $200 \mu \mathrm{L}$ of conjugate solution was added to the wells. The wells were then washed again and filled with $200 \mu \mathrm{L}$ of TMB color developing agent at $37^{\circ} \mathrm{C}$ in the dark for 30 minutes. Finally, 100 $\mu \mathrm{L}$ of Stop Solution was added to each well and absorbance was measured at $450 \mathrm{~nm}$ by using a microtest plate spectrophotometer. MMP-9 levels were quantified with a calibration curve by using human MMP-9 as a standard.

\section{Statistical analysis}

Continuous value was expressed as the mean \pm $\mathrm{SE}$ and the categorical variables were expressed as percentages. Comparability of groups was analyzed by the Mann-Whitney $U$ test, $x^{2}$ test or the Fisher exact test, as suitable. The statistical significance of the means for plasma MMP-9 was determined by a Mann-Whitney $U$ test between groups and analyzed by pair sample t-test between acute and remission stage of VAP. A linear regression analysis was used to identify correlations between MMP-9 concentration and the CPIS and laboratory variables. The cutoff concentrations were estimated according to their receiver operating characteristic curves and identified using the Youden index. Test performance evaluated by Likelihood ratios. Statistical analysis was performed using the SPSS 15.0 statistics software (SPSS Inc., Chicago, IL USA). A $p<0.05$ was considered statistically significant.

\section{Results}

In total, 72 patients were recruited for this study: 30 healthy volunteers, 12 patients without VAP, and 30 patients with VAP; their clinical and demographic characteristics are summarized in Table 1 . The healthy volunteers were significantly younger in age compared with both patients with VAP $(35.73 \pm 2.20$ vs. $64.30 \pm 3.19, p<0.001)$ and patients without VAP $(35.73 \pm 2.20$ vs. $52.67 \pm 5.80, p=0.01)$. White blood cell counts (WBCs) and neutrophil levels were significantly higher in patients with VAP $(p<0.001$; Table 1). Compared with patients with VAP, surgical operation was the primary reason for initiating ventilation support in patients without VAP $(p=0.02$; Table 1). At study enrollment, the severity of VAP, identified by the CPIS, was significantly higher in patients with VAP when compared with patients without $\operatorname{VAP}(p<0.001$; Table 1$)$.

Table 1. Clinical and demographic details of patients with VAP, non-VAP and healthy control subjects.

\begin{tabular}{|c|c|c|c|}
\hline Characteristics & VAP & non-VAP & Control \\
\hline & $(n=30)$ & $(n=12)$ & $(n=30)$ \\
\hline Age (yrs) & $64.30 \pm 3.19$ & $52.67 \pm 5.80$ & $35.73 \pm 2.20 \mathrm{a}, \mathrm{b}$ \\
\hline Male gender & $25(83.3 \%)$ & $8(66.7 \%)$ & $27(90.0 \%)$ \\
\hline \multicolumn{4}{|l|}{$\begin{array}{l}\text { Inflammation markers at study } \\
\text { enrollment }\end{array}$} \\
\hline $\mathrm{WBC}\left(/ \mathrm{mm}^{3}\right)$ & $\begin{array}{l}16476.67 \pm \\
1158.26\end{array}$ & $\begin{array}{l}8350.00 \pm \\
953.73 \mathrm{a}\end{array}$ & $\begin{array}{l}7049.67 \pm \\
281.37 \mathrm{a}\end{array}$ \\
\hline Neutrophils (/mm3) & $\begin{array}{l}13285.40 \pm \\
1088.20\end{array}$ & $\begin{array}{l}5264.56 \pm \\
898.17 \mathrm{a}\end{array}$ & $\begin{array}{l}4058.63 \pm \\
208.82^{a}\end{array}$ \\
\hline CRP (ng/dl) & $16.15 \pm 1.69$ & - & - \\
\hline \multicolumn{4}{|l|}{$\begin{array}{l}\text { Reason for mechanical } \\
\text { ventilation }\end{array}$} \\
\hline Surgical & $11(36.7 \%)$ & $10(83.3 \%)^{a}$ & \\
\hline Pneumonia & $2(6.7 \%)$ & 0 & \\
\hline $\begin{array}{l}\text { Pleural effusion / Pulmonary } \\
\text { edema }\end{array}$ & $4(13.3 \%)$ & 0 & \\
\hline COPD with Acute Exacerbation & $1(3.3 \%)$ & 0 & \\
\hline Cardiac arrest & $2(6.7 \%)$ & 0 & \\
\hline Renal failure & $1(3.3 \%)$ & 0 & \\
\hline Neurologic failure & $6(20.0 \%)$ & $1(8.3 \%)$ & \\
\hline Cardiovascular & 0 & $1(8.3 \%)$ & \\
\hline Hypovomemic shock & $4(13.3 \%)$ & 0 & \\
\hline Sepsis & $4(13.3 \%)$ & 0 & \\
\hline \multicolumn{4}{|l|}{ Coexisting illnesses } \\
\hline Pulmonary & $4(13.3 \%)$ & $1(8.3 \%)$ & \\
\hline Cardiac & $8(26.7 \%)$ & $3(25.0 \%)$ & \\
\hline Liver & $3(10.0 \%)$ & 0 & \\
\hline Renal & $4(13.3 \%)$ & 0 & \\
\hline Cancer & $10(33.3 \%)$ & $7(58.3 \%)$ & \\
\hline Cerebral vascular accident & $4(13.3 \%)$ & $3(25.0 \%)$ & \\
\hline \multicolumn{4}{|l|}{ Scores at study enrollment } \\
\hline CPIS & $6.40 \pm 0.27$ & $1.58 \pm 0.26^{a}$ & \\
\hline
\end{tabular}

WBC, white blood cell; CRP, C-reactive protein; COPD, chronic obstructive pulmonary disease; CPIS, Clinical Pulmonary Infection Score; VAP, ventilator-associated pneumonia; discrete variables are expressed as counts (\%) and continuous variables as mean $\pm \mathrm{SE}$. a $p$ value $<0.05$ was considered significant in patients of VAP v.s non-VAP or health control subjects, $\mathrm{b} p$ value $<0.05$ was considered significant in patients of non-VAP v.s healthy control subjects.

Respiratory data are displayed in Figure 1. The PF ratio of patients without VAP was close to the control group. Moreover, the $\mathrm{PF}$ ratio and the oxygenation index were worse in patients with VAP when compared with patients without VAP $(p<$ 0.001). Microbiological data-divided into gram-positive and gram-negative bacterial data - from SQ-EA identification of VAP are given in Table 2.

A gelatin zymography assay measured plasma MMP-9 activity to have significantly increased in the acute stage of patients with VAP compared with both patients without VAP $(p=0.009)$ and the control group ( $p=0.009)$ and to have significantly decreased after treatment $(p=0.0008)$ (Figure 2).

Concentration of plasma MMP-9 in patients with $\mathrm{VAP}$, patients without $\mathrm{VAP}$, and the control group are 
displayed in Figure 3. Plasma MMP-9 levels were significantly increased in the acute stage of VAP patients $(193.86 \pm 25.04 \mathrm{ng} / \mathrm{mL})$ when compared with patients without VAP $(80.17 \pm 15.94 \mathrm{ng} / \mathrm{mL} ; p=$ $0.0038)$ and the control group $(58.09 \pm 3.87 \mathrm{ng} / \mathrm{mL} ; p<$ 0.0001) respectively. Plasma MMP-9 levels significantly decreased after treatment $(127.05 \pm 15.62$ $\mathrm{ng} / \mathrm{mL} ; p=0.01)$. However, there's no difference between patients without VAP and the control group $(p=0.40)$. Furthermore, when compared with the control group, the plasma MMP-9 level was significantly elevated in patients with VAP both in the acute $(p<0.0001)$ and remission stages $(\mathrm{p}=0.0007)$ (Figure 3).

(A)

(B)

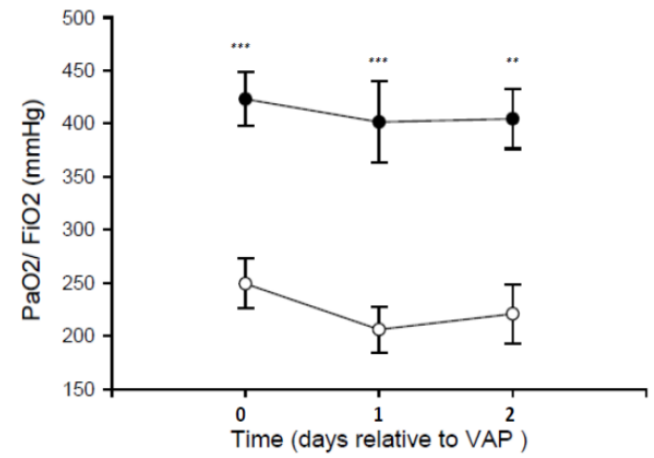

Table 2. Isolated pathogens in patients of VAP.

\begin{tabular}{ll}
\hline Bacteria & Number of patients \\
\hline Gram-positive bacteria & $3(10.0 \%)$ \\
S. aureus & \\
Gram-negative bacteria & $14(46.7 \%)$ \\
Acinetobacter baumannii & $13(43.3 \%)$ \\
P. aeruginosa & $11(36.7 \%)$ \\
S. maltophilia & $6(20.0 \%)$ \\
Enterobacter aerogenes & $5(16.7 \%)$ \\
Elizabethkingia meningoseptica & $4(13.3 \%)$ \\
Klebsiella pneumoniae & $2(6.7 \%)$ \\
Sphingomonas paucimobilis & $1(3.3 \%)$ \\
E. coli & $1(3.3 \%)$ \\
S. marcescens & $1(3.3 \%)$ \\
Citrobacter koseri & $1(3.3 \%)$ \\
P. mirabilis & $1(3.3 \%)$ \\
Morganella &
\end{tabular}

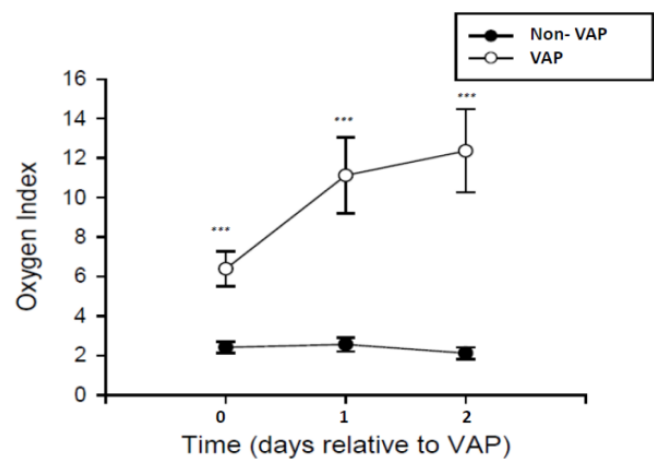

Figure 1. Respiratory data in 30 patients with VAP and 12 non-VAP subjects. (A) Ratio of the partial pressure of oxygen in arterial blood ( $\mathrm{PaO}$ ) to the inspired oxygen fraction ( $\mathrm{FiO}$ ) and (B) Oxygen index in patients developing ventilator-associated pneumonia (square) and non-VAP patients (circle) with mechanical ventilator. * $\mathrm{p}<0.05$, ** $p<0.01, * * * p<0.001$ by Mann Whitney U test.
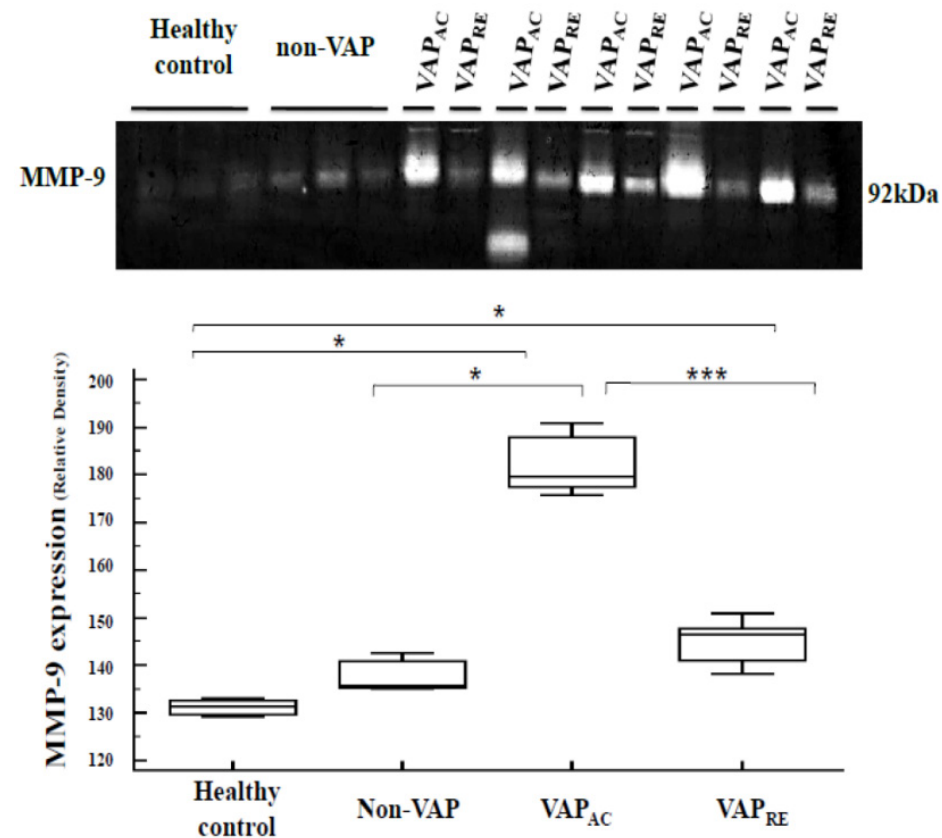

Figure 2. Plasma MMP-9 expression were analyzed by gelatin zymography assay obtained from the healthy control, non-VAP subjects and patients with VAP. Plasma MMP-9 expression was significantly increased in the acute stage of VAP patients when compared with both the non-VAP subjects $(p=0.009)$ and the healthy controls $(p=0.009)$; and decreased after treatment $(p=0.0008)$. Box plot represent the median, 25 th to 75 th percentiles, minimum, maximum, and outliers. VAPAC, VAP in acute stage, VAPRE, VAP in remission stage. 


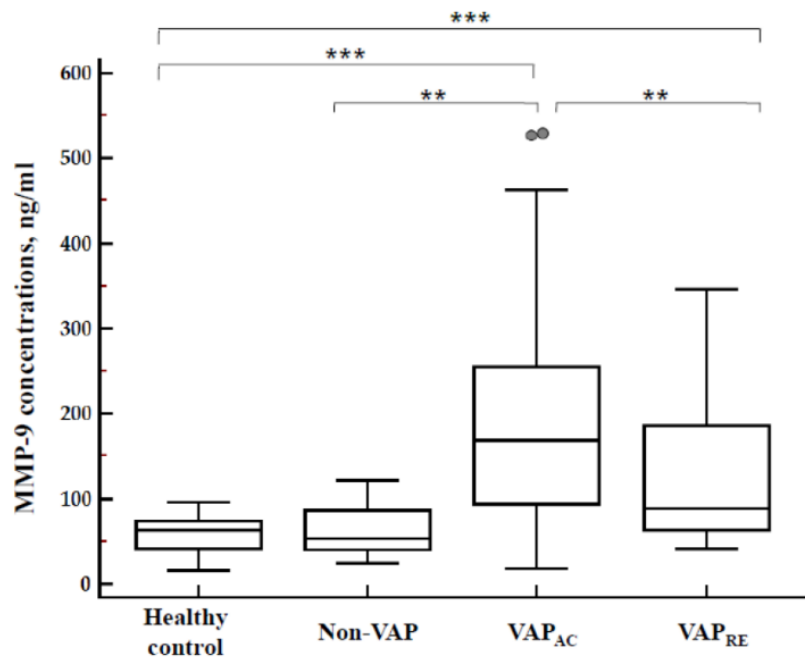

Figure 3. Concentration of plasma MMP-9 in 30 healthy control, 12 non-VAP subjects and 30 patients with VAP who were divided into acute and remission stage by ELISA kits. MMP-9 concentration was significantly higher in the acute stage of VAP patients when compared with non-VAP subjects $(p=0.0038)$ and healthy controls $(p<0.0001)$; and significantly decreased after the treatment $(p=0.01)$. There's no difference between non-VAP subjects and healthy controls $(\mathrm{p}=0.40)$. Plasma MMP-9 levels were significantly increased in VAP patients both in the acute $(p<0.0001)$ and remission stages $(p=0.0007)$, when compared with healthy controls.

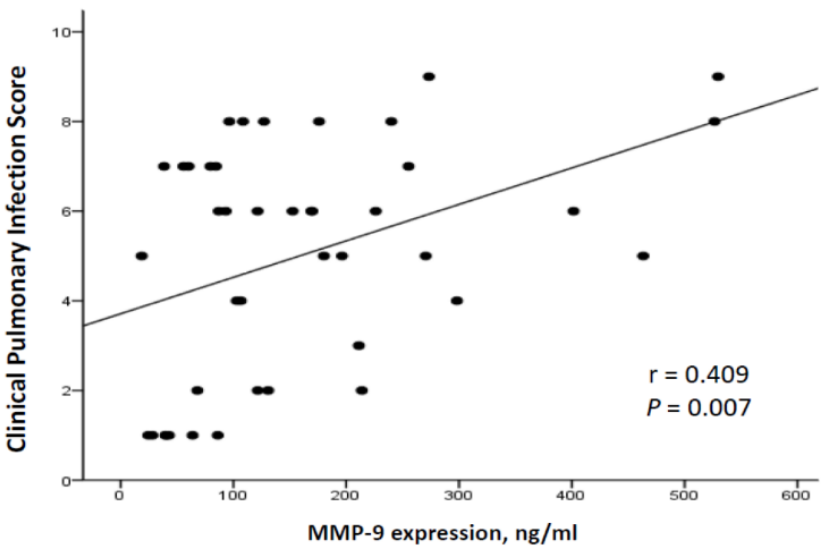

Figure 4. Correlation of plasma MMP-9 with CPIS scores in 42 ventilated subjects. There was a positive correlation between MMP-9 and CPIS (General linear model, $r=0.409, p=0.007, n=42$ ).

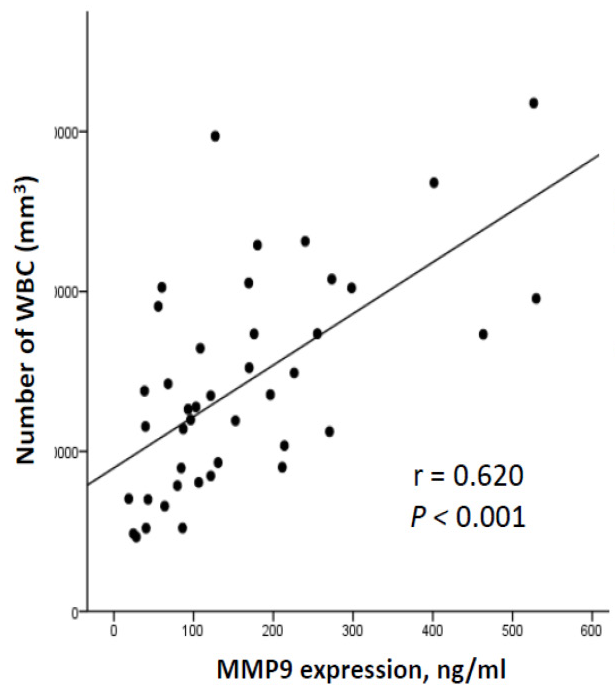

To investigate the correlation between the severity of VAP and MMP-9 levels, we adopted the CPIS as a surrogate for the severity of pneumonia. The correlation between CPIS and MMP-9 concentrations in our 42 patients with ventilation is illustrated in Figure 4. A positive correlation was noted between MMP-9 and the CPIS ( $r=0.409, p=0.007$; Figure 4). Furthermore, MMP-9 concentrations correlated positively with the quantity of WBCs $(\mathrm{r}=0.620, p<$ $0.001)$ as well as the neutrophil counts $(r=0.335, p=$ 0.035) (Figure 5).

We constructed ROC curves to determine the diagnostic accuracy of plasma MMP-9 levels for VAP. At a cutoff level of $92.62 \mathrm{ng} / \mathrm{mL}$, the area under the curve for MMP-9 was 0.863 (95\% CI $=0.761$ to $0.932 ; p$ $<0.0001$ ), and the sensitivity, specificity, positive and negative predictive values, and the likelihood of positive and negative results of VAP were $76.67 \%$, $88.10 \%, 82.10 \%, 84.10 \%, 6.44$, and 0.26 , respectively (Figure 6).

\section{Discussion}

The current study yielded 3 major results. First, the plasma MMP-9 level was significantly elevated in the acute stage of patients with VAP compared with both the control group and patients without VAP. MMP-9 decreased drastically after effective treatment. Second, plasma MMP-9 concentration was positively correlated with the CPIS score, quantity of WBCs, and neutrophils counts. Third, plasma MMP-9 was excellent in recognizing VAP.

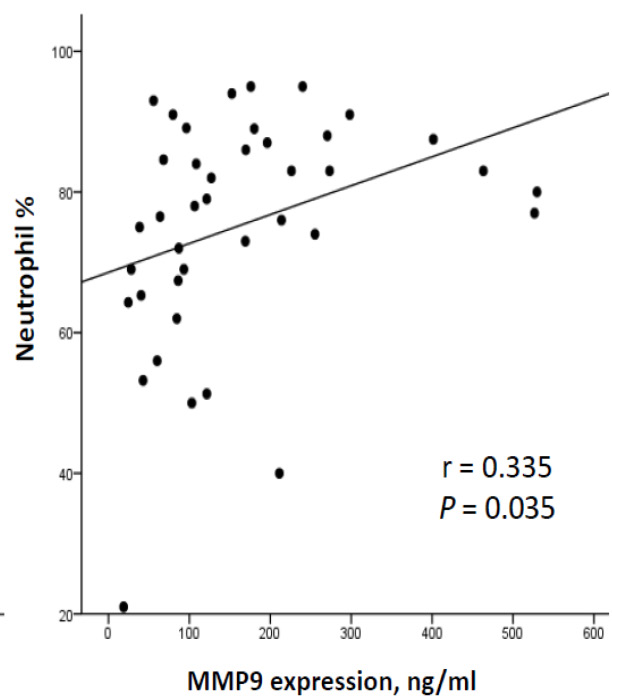

Figure 5. Correlation of plasma MMP-9 with WBCs and neutrophils in 42 ventilated subjects. There was a signification correlation between MMP-9 and WBCs (General linear model, $r=0.620, p<0.001, n=42$ ) as well as neutrophils counts (General linear model, $r=0.335, p=0.035, n=40$ ). 


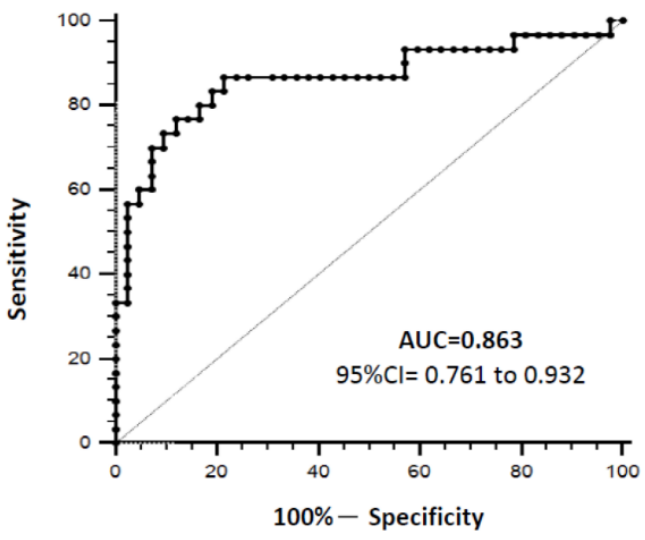

\begin{tabular}{llllllll}
\hline & $\begin{array}{l}\text { Optimal Cut-off } \\
(\mathrm{ng} / \mathrm{ml})\end{array}$ & $\begin{array}{l}\text { Sensitivity } \\
\%\end{array}$ & $\begin{array}{l}\text { Specificity } \\
\%\end{array}$ & PPV \% & NPV \% & LR $^{+}$ & LR $^{-}$ \\
\hline MMP-9 & 92.62 & 72.67 & 88.10 & 82.1 & 84.1 & 6.44 & 0.26 \\
\hline
\end{tabular}

Figure 6. Receiver operating characteristic (ROC) curves and optimal sensitivity, specificity, positive and negative predicative values (PPV and NPV), as well as the likelihood rations of positive and negative results (LR+ and LR-) of the VAP.

The diagnosis of VAP was usually made based on clinical features, chest imaging, and respiratory sampling. However, there are drawbacks pertaining to poor specificity [14, 15] and oversensitive [16]. Radiographic abnormalities alone are insufficient to diagnose VAP and are often nonspecific. Although it is ideal to sample the respiratory tract specimen prior to the initiation of antibiotic therapy, the severity of illness and the risk of delaying the treatment should also be considered [3]. Therefore, a reliable and timely method for diagnosing VAP is necessary. Over the past few years, numerous proteins have been reported as potential biological markers for diagnosing VAP [1, 2]. However, these biomarkers had to be sampled bronchoscopically in the bronchoalveolar lavage fluid (BALF), which is invasive and difficult because it necessitates the presence of an experienced clinician. By contrast, blood samples can be easily drawn and avoids the injuries associated with invasive procedures [17]. VAP is associated with an increase in capillary permeability, and the pulmonary proteins that leak into circulation may serve as biological markers [18, 19]. The present study successfully utilized plasma MMP-9 for diagnosing VAP, and it demonstrated excellent sensitivity and specificity.

MMP-9 belongs to a large family of matrix metalloproteinases (MMPs), which are extracellular proteinases known to degrade the extracellular matrix (ECM) and are involved in immune response [7]. Focusing on the role of MMP-9 in pneumonia, Brown et al. reported that MMP-9 is essential in maintaining immune response by activating specific proteins, promoting neutrophil migration, generating reactive oxygen species, and enhancing bacterial phagocytosis $[7,20]$. El-Solh [21] and Wilkinson [22] have reported that patients with VAP usually have higher concentration of MMP-8 and MMP-9 in their BALF. In our study, we also discovered that the plasma MMP-9 level was significantly elevated in the acute stage of patients with VAP compared with both the control group and patients without VAP. This result concurs with our previous reports and supports the proposal that MMP-9 may play a significant role in various pulmonary inflammatory diseases [23, 24].

The CPIS was suggested by Pugin et al. [25]; it combines clinical, physiological, radiological, and microbiological data (fever, blood leukocytes, purulence of tracheal secretions, oxygenation, radiographic abnormality, and results of sputum culture and Gram stain) [25, 26], all of which has been reported to be associated with a high possibility of pneumonia. However, in the subsequent study, Croce et al. evaluated 158 patients suspected of having VAP, as validated by a BAL culture. The CPIS had a sensitivity of $61 \%$ and a specificity of $43 \%$ [27]. Fartoukh et al. studied 68 patients suspected of VAP using the CPIS score and compared the findings with diagnoses established using a plugged telescoping catheter (PTC) or BAL culture. The CPIS yielded a sensitivity of $60 \%$ and a specificity of $59 \%$ [28]. Overall, the sensitivity and specificity of the score were below expectations. In the following study, a modified CPIS was applied by Singh et al. and was used as an indicator to determine whether a patient could receive a shorter course of antibiotics therapy rather than to diagnose VAP [29]. Gursel et al. reported that the CPIS was higher in nonsurvivors of VAP, but the predictive value of CPIS in the mortality of patients with VAP was disappointing [30]. In our study, we determined that there is a positive correlation between CPIS and MMP-9 concentrations, but the correlation coefficient $(\mathrm{r})$ is less than 0.5 . 
Moreover, the correlation between MMP-9 level, PF ratio $(\mathrm{r}=0.25, p=0.13)$, and the oxygenation index $(\mathrm{r}=$ $0.27, p=0.10$ ) was low, which limits the value of MMP-9 as a surrogate for the severity of pneumonia. Additional studies are necessary to confirm the relationship between the severity of pneumonia and MMP-9.

MMP-9 is majorly synthesized and stored in monocytes/macrophages, neutrophils, and eosinophils and is secreted in an inducible manner $[23,31]$. Certain inflammatory cytokines can induce MMP-9 release in various cells, such as Clara cells, macrophages, fibroblasts, alveolar type II cells, smooth muscle cells, and bronchial epithelial cells [24, 32 ,33]. This may explain why the concentration of MMP-9 is positively correlated with the quantity of WBCs as well as the neutrophil count in this study.

In the literature, mechanical ventilation can cause lung injury and worsen pre-existing lung damage (termed ventilator-induced lung injury (VILI)). This injury is characterized by a pulmonary inflammatory reaction, barrier disruption, airspace edema, cell injury, and apoptosis [34, 35]. Kim et al. demonstrated that VILI mediated by neutrophilic inflammation was closely related to the expression and activity of MMP-9 [36]. Similarly, Schaaf et al. displayed that artificial ventilation was associated with increased MMP-9 concentration and activation in mini-BAL [37]. In this present study, because mechanical ventilation may cause VILI and may be related to the release of MMP-9, the control group was studied to eliminate the interference of artificial ventilation. Because MMP-9 is involved in both physiological and pathological processes [13], only nonhospitalized patients were included in this group. These healthy control volunteers, who were all young (mean age $<40 \mathrm{y}$ ), may have led to a selection bias and caused study limitations. No difference in plasma MMP-9 levels was noted between patients without $\mathrm{VAP}$ and the control group $(p=0.40)$ (Figure 3A). We presumed that the risk of VILI in our non-VAP control group was probably low, because the peak airway pressure in patients without VAP was low (peak airway pressure $=20 \pm 1.17 \mathrm{~cm} \mathrm{H}_{2} \mathrm{O}$ on day 1 of study enrollment), whereas the tidal volume was not high (tidal volume per ideal body weight $=10.33 \pm 0.36$ $\mathrm{mL} / \mathrm{kg}$ on day 1 of the study enrolment) and ventilator duration was short (3.55 \pm 0.39 days). Bias could also exist because the sample size in our study was small. This result relates to Wilkinson et al. because in their microbiologically confirmed patients with VAP, there were no significant differences in BALF MMP-9 between patients without VAP and the control group [22]. Additional studies are required to discern the relationship between MMP-9 and artificial ventilation-related VILI.

In conclusion, increased plasma MMP-9 concentrations could play a significant role in the pathogenesis of VAP, and MMP-9 might be a useful biomarker that could aid the diagnosis of VAP. However, in patients who have more systemic inflammation, the specific link between MMP-9 and VAP remains to be clarified.

\section{Acknowledgements}

The study was supported by the Chung Shan Medical University Hospital (CSH-2013-C-008).

\section{Competing interests}

The authors declare no conflict of interest.

\section{References}

[1] Rea-Neto A, Youssef NC, Tuche F, Brunkhorst F, Ranieri VM, Reinhart K and Sakr Y. Diagnosis of ventilator-associated pneumonia: a systematic review of the literature. Crit Care 2008; 12: R56.

[2] Joseph NM, Sistla S, Dutta TK, Badhe AS and Parija SC. Ventilator-associated pneumonia: a review. Eur J Intern Med 2010; 21: 360-368.

[3] Craven DE, Hudcova J and Lei Y. Diagnosis of ventilator-associated respiratory infections (VARI): microbiologic clues for tracheobronchitis (VAT) and pneumonia (VAP). Clin Chest Med 2011; 32: 547-557.

[4] Palazzo SJ, Simpson T and Schnapp L. Biomarkers for ventilator-associated pneumonia: review of the literature. Heart Lung 2011; 40: 293-298.

[5] Van den Steen PE, Dubois B, Nelissen I, Rudd PM, Dwek RA and Opdenakker G. Biochemistry and molecular biology of gelatinase B or matrix metalloproteinase-9 (MMP-9). Crit Rev Biochem Mol Biol 2002; 37: 375-536.

[6] Atkinson JJ and Senior RM. Matrix metalloproteinase-9 in lung remodeling. Am J Respir Cell Mol Biol 2003; 28: 12-24.

[7] Chiang TY, Tsao SM, Yeh CB and Yang SF. Matrix metalloproteinases in pneumonia. Clin Chim Acta 2014; 433: 272-277.

[8] Brown GM BD, Donaldson K, Drost E, MacNee W. Neutrophil sequestration in rat lungs. Thorax 1995; 50: 661-667.

[9] Chen Z, Shao X, Dou X, Zhang X, Wang Y, Zhu C, Hao C, Fan M, Ji W and Yan Y. Role of the Mycoplasma pneumoniae/Interleukin-8/Neutrophil Axis in the Pathogenesis of Pneumonia. PLoS One 2016; 11: e0146377.

[10] Hong JS, Greenlee KJ, Pitchumani R, Lee SH, Song LZ, Shan M, Chang SH, Park PW, Dong C, Werb Z, Bidani A, Corry DB and Kheradmand F. Dual protective mechanisms of matrix metalloproteinases 2 and 9 in immune defense against Streptococcus pneumoniae. J Immunol 2011; 186: 6427-6436.

[11] American Thoracic S and Infectious Diseases Society of A. Guidelines for the management of adults with hospital-acquired, ventilator-associated, and healthcare-associated pneumonia. Am J Respir Crit Care Med 2005; 171: 388-416

[12] Yeh CM, Lin CW, Yang JS, Yang WE, Su SC and Yang SF. Melatonin inhibits TPA-induced oral cancer cell migration by suppressing matrix metalloproteinase-9 activation through the histone acetylation. Oncotarget 2016;

[13] Chiang TY, Yu YL, Lin CW, Tsao SM, Yang SF and Yeh CB. The circulating level of MMP-9 and its ratio to TIMP-1 as a predictor of severity in patients with community-acquired pneumonia. Clin Chim Acta 2013; 424: 261-266.

[14] Wunderink RG. Clinical criteria in the diagnosis of ventilator-associated pneumonia. Chest 2000; 117: 191S-194S.

[15] Niederman MS. The clinical diagnosis of ventilator-associated pneumonia. Respir Care 2005; 50: 788-796; discussion 807-712.

[16] Porzecanski I and Bowton DL. Diagnosis and treatment of ventilator-associated pneumonia. Chest 2006; 130: 597-604.

[17] Determann RM, Millo JL, Waddy S, Lutter R, Garrard CS and Schultz MJ Plasma CC16 levels are associated with development of ALI/ARDS in patients with ventilator-associated pneumonia: a retrospective observational study. BMC Pulm Med 2009; 9: 49.

[18] Ratjen F, Havers $\mathrm{W}$ and Braun J. Intrapulmonary protein leakage in immunocompromised children and adults with pneumonia. Thorax 1999; 54: $432-436$

[19] Witzenrath M, Gutbier B, Hocke AC, Schmeck B, Hippenstiel S, Berger K, Mitchell TJ, de los Toyos JR, Rosseau S, Suttorp N and Schutte H. Role of pneumolysin for the development of acute lung injury in pneumococcal pneumonia. Crit Care Med 2006; 34: 1947-1954.

[20] Brown GM, Brown DM, Donaldson K, Drost E and MacNee W. Neutrophil sequestration in rat lungs. Thorax 1995; 50: 661-667. 
[21] El-Solh AA, Amsterdam D, Alhajhusain A, Akinnusi ME, Saliba RG, Lynch SV and Wiener-Kronish JP. Matrix metalloproteases in bronchoalveolar lavage fluid of patients with type III Pseudomonas aeruginosa pneumonia. J Infect 2009; 59: 49-55.

[22] Wilkinson TS, Morris AC, Kefala K, O'Kane CM, Moore NR, Booth NA, McAuley DF, Dhaliwal K, Walsh TS, Haslett C, Sallenave JM and Simpson AJ. Ventilator-associated pneumonia is characterized by excessive release of neutrophil proteases in the lung. Chest 2012; 142: 1425-1432.

[23] Yang SF, Chu SC, Chiang IC, Kuo WF, Chiou HL, Chou FP, Kuo WH and Hsieh YS. Excessive matrix metalloproteinase-9 in the plasma of community-acquired pneumonia. Clin Chim Acta 2005; 352: 209-215.

[24] Chiang TY, Shyu LY, Tsao TC, Chien MH, Tsao SM, Lee YT and Yang SF. Elevated plasma matrix metalloproteinase-9 protein and its gene polymorphism in patients with community-acquired pneumonia. Clin Chem Lab Med 2012; 50: 449-454.

[25] Pugin J, Auckenthaler R, Mili N, Janssens JP, Lew PD and Suter PM. Diagnosis of ventilator-associated pneumonia by bacteriologic analysis of bronchoscopic and nonbronchoscopic "blind" bronchoalveolar lavage fluid. Am Rev Respir Dis 1991; 143: 1121-1129.

[26] Torres A and Carlet J. Ventilator-associated pneumonia. European Task Force on ventilator-associated pneumonia. Eur Respir J 2001; 17: 1034-1045.

[27] Croce MA, Swanson JM, Magnotti LJ, Claridge JA, Weinberg JA, Wood GC, Boucher BA and Fabian TC. The futility of the clinical pulmonary infection score in trauma patients. J Trauma 2006; 60: 523-527; discussion 527-528.

[28] Fartoukh M, Maitre B, Honore S, Cerf C, Zahar JR and Brun-Buisson C. Diagnosing pneumonia during mechanical ventilation: the clinical pulmonary infection score revisited. Am J Respir Crit Care Med 2003; 168: 173-179.

[29] Singh N, Rogers P, Atwood CW, Wagener MM and Yu VL. Short-course empiric antibiotic therapy for patients with pulmonary infiltrates in the intensive care unit. A proposed solution for indiscriminate antibiotic prescription. Am J Respir Crit Care Med 2000; 162: 505-511.

[30] Gursel G and Demirtas S. Value of APACHE II, SOFA and CPIS scores in predicting prognosis in patients with ventilator-associated pneumonia. Respiration 2006; 73: 503-508.

[31] Takafuji S, Ishida A, Miyakuni Y and Nakagawa T. Matrix metalloproteinase-9 release from human leukocytes. J Investig Allergol Clin Immunol 2003; 13: $50-55$.

[32] Zhang B, Ye S, Herrmann SM, Eriksson P, de Maat M, Evans A, Arveiler D, Luc G, Cambien F, Hamsten A, Watkins H and Henney AM. Functional polymorphism in the regulatory region of gelatinase $\mathrm{B}$ gene in relation to severity of coronary atherosclerosis. Circulation 1999; 99: 1788-1794.

[33] Ye S. Influence of matrix metalloproteinase genotype on cardiovascular disease susceptibility and outcome. Cardiovasc Res 2006; 69: 636-645.

[34] Kuipers MT, van der Poll T, Schultz MJ and Wieland CW. Bench-to-bedside review: Damage-associated molecular patterns in the onset of ventilator-induced lung injury. Crit Care 2011; 15: 235.

[35] Slutsky AS and Ranieri VM. Ventilator-induced lung injury. N Engl J Med 2013; 369: 2126-2136

[36] Kim JH, Suk MH, Yoon DW, Lee SH, Hur GY, Jung KH, Jeong HC, Lee SY, Lee SY, Suh IB, Shin C, Shim JJ, In KH, Yoo SH and Kang KH. Inhibition of matrix metalloproteinase-9 prevents neutrophilic inflammation in ventilator-induced lung injury. Am J Physiol Lung Cell Mol Physiol 2006; 291: L580-587.

[37] Schaaf B, Liebau C, Kurowski V, Droemann D and Dalhoff K. Hospital acquired pneumonia with high-risk bacteria is associated with increased pulmonary matrix metalloproteinase activity. BMC Pulm Med 2008; 8: 12. 